\title{
DA PERDA DE LEGITIMIDADE À POLARIZAÇÃO: os partidos e os sistemas partidários de Argentina e Venezuela
}

\author{
João Carlos Amoroso Botelho*
}

\begin{abstract}
O artigo atualiza as classificações de Coppedge (1997) para os partidos de Argentina e Venezuela, agregando às dimensões originais - esquerda-direita e cristão ou secular - três outras: programático ou clientelista, materialista ou pós-materialista e apelo eleitoral étnico. Para fazê-lo, se fundamenta na literatura e em um survey com especialistas. Uma conclusão é que houve pouca variação em relação às avaliações de Coppedge, com os principais partidos concentrados em torno do centro, à exceção do PSUV, na Venezuela, que foi classificado como de esquerda secular. Quanto aos sistemas partidários, os dois países transitaram da perda de legitimidade dos partidos tradicionais até o início dos anos 2000 para cenários que se caracterizavam, no momento dessa classificação, pela polarização em torno da adesão ou da oposição ao kirchnerismo ou ao chavismo. Ao contrário do caso venezuelano, a polarização na Argentina era mais entre apoiar ou se opor ao governo de turno do que em termos ideológicos.
\end{abstract}

PAlavras-chave: Classificação. Ideologia. Partidos. Argentina. Venezuela.

\section{INTRODUÇÃO}

$\mathrm{O}$ artigo parte das classificações de Coppedge (1997) e se fundamenta em dados extraídos de duas fontes, a revisão da literatura e um survey com especialistas (indicados no Anexo), para classificar os partidos da Argentina e da Venezuela e traçar um panorama dos sistemas partidários dos dois países, até o momento a que se referem as novas classificações. Além de atualizar as avaliações de Coppedge para as forças políticas da Argentina e da Venezuela, o trabalho, que integra um projeto maior de classificação de partidos latino-americanos, ${ }^{1}$ agrega às dimensões originais - esquerda ou direita e cristão ou secular - três outras, a saber: programático ou clientelista, materialista ou pós-materialista e existência ou não de apelo eleitoral étnico.

* Universidade Federal de Goiás. Faculdade de Ciências Sociais. Prédio de Humanidades, sala 23. Campus II. Cep: 74001970. Goiânia - Goiás - Brasil. joaocarlosbotelho@hotmail.com

${ }^{1}$ Sob a coordenação das professoras Denise Paiva Ferreira (UFG) e Gabriela da Silva Tarouco (UFPE), com o título de "Mensurando a ideologia dos partidos políticos na América Latina: uma atualização da classificação de Michael Coppedge 15 anos depois”, o projeto foi aprovado e contemplado com auxílio financeiro na Chamada CNPq/MCTI ${ }^{\circ}$ 25/2015 - Ciências Humanas, Sociais e Sociais Aplicadas.
O interesse na Argentina e na Venezuela se deve ao fato de que são dois países que chegaram a ter seus sistemas partidários considerados como modelos de consolidação na América Latina (Lamounier, 1992) e que, posteriormente, passaram por períodos de instabilidade democrática e perda de legitimidade de seus partidos tradicionais, com resultados que apresentam diferenças e semelhanças em relação ao universo partidário. O estudo de Coppedge foi o primeiro a sistematizar a classificação ideológica dos partidos latino-americanos, oferecendo uma base para comparações. Por isso, tem sido amplamente utilizado por analistas que mobilizam a ideologia partidária como variável explicativa para uma grande variedade de objetos, desde coligações eleitorais até políticas públicas, ainda que muitos partidos que surgiram e se tornaram importantes desde então não constem dessa lista, assim como muitos dos que constam podem ter se movido na escala esquerda-direita. Dessa forma, uma atualização ou revisão da classificação se torna necessária.

$\mathrm{O}$ artigo de Coppedge pretendia, originalmente, identificar a distribuição do apoio eleitoral, medido pela porcentagem de votos, 
entre os blocos ideológicos de partidos na América Latina. A repercussão maior, porém, não foi da força eleitoral dos blocos, mas da mensuração da variável independente, realizada para operacionalizar a análise, cuja metodologia acabou se consolidando como uma medida válida e confiável da ideologia dos partidos latino-americanos. Desde então, a classificação de Coppedge tem sido utilizada por autores de distintas áreas em vários países, como Pippa Norris, Susan Stokes, Joseph Colomer, Gary Cox, Mathew McCubbins, Eduardo Alemán e George Tsebelis, e aparecia com 352 citações no Google Scholar até a última verificação. Esse impacto sugere que a abordagem utilizada tem respaldo na comunidade científica e que seus resultados merecem ser atualizados ou revistos, seja para o conjunto de países latino-americanos incluídos no estudo original, seja para alguns deles, como a Argentina e a Venezuela.

\section{METODOLOGIA}

Os partidos considerados na análise foram os que elegeram pelo menos um representante para a Câmara Baixa desde as redemocratizações até as últimas eleições legislativas

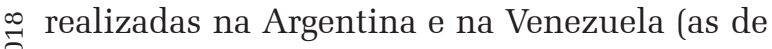
2013 e 2010), antes da distribuição dos ques遂 tion tionários aos especialistas. O período foi definido de forma a ser o mais abrangente possível, para que, assim, a classificação incorporasse o maior número possível de partidos. Em ambos os países, ele se inicia com a posse dos presidentes eleitos pelo voto popular para marcar o fim de regimes autoritários, que foram Raúl Alfonsín, em 1983 na Argentina, e Rómulo Betancourt, em 1959 na Venezuela. Os respectivos períodos, então, vão de 1983 a 2013 e de 1959 a 2010. Com isso, a eleição legislativa de 1958 não entra na amostra sobre a Venezuela, fazendo com que as primeiras consideradas sejam as seguintes, de 1963.

A definição dos períodos, portanto, não se baseia em julgamentos próprios ou de terceiros sobre a qualidade democrática na Argentina e na Venezuela, já que a proposta do trabalho é a classificação de partidos, e não de eleições ou regimes. Ainda que o parâmetro de seleção fosse a qualidade das eleições, os períodos variariam pouco, já que, de todos os pleitos que foram considerados aqui, o único que não passa pelo crivo de Mainwaring e Pérez-Liñán (2013), por exemplo, é o de 2010 na Venezuela. Nesse caso, a última eleição seria a de 2005, o que não se justificaria, pois haveria mais razões para excluir aquele pleito, que foi boicotado pela oposição, do que o de 2010, em que as forças oposicionistas voltaram a participar.

As classificações avaliam os partidos quanto às seguintes dimensões: posição no eixo esquerda e direita, condições quanto a ser cristão ou ser secular, programático ou clientelista e materialista ou pós-materialista, bem como quanto à existência ou não de apelo eleitoral étnico. Cada dimensão tem suas categorias, com as respectivas definições, que serão apresentadas posteriormente.

Das cinco dimensões, as duas primeiras são as mesmas que foram consideradas por Coppedge (1997). As outras três foram incluídas de forma a complementar e atualizar as originais. As dimensões de programático ou clientelista e apelo eleitoral étnico se referem a aspectos específicos da dinâmica político-partidária na América Latina. Uma literatura extensa, com enfoque regional ou nacional, tem explorado as práticas clientelistas das quais partidos e políticos latino-americanos se servem para angariar votos e poder (Amaral; Stokes, 2005; Stokes et al., 2013), ou, por outro lado, a divisão programática que estrutura certos sistemas partidários da região (Kitschelt et al., 2010). A política étnica também se tornou uma característica da competição eleitoral em parte da América Latina em que indígenas e mestiços são mais numerosos, o que atraiu o interesse de estudiosos desde que movimentos e partidos com apelo étnico ganharam força na primeira metade dos anos 2000 (Madrid, 2012; Van Cott, 2005). 
A dimensão materialista ou pós-materialista, por sua vez, acompanha a importância que o trabalho de Inglehart e colaboradores (1990, 2005) conferiu ao tema. Para esses autores, as sociedades industriais avançadas passaram por uma mudança cultural em que valores relativos à sobrevivência material perderam espaço para valores que enfatizam autoexpressão e qualidade de vida, originando demandas por proteção ao meio ambiente, respeito a minorias e liberdades individuais. A emergência desses temas separaria indivíduos e partidos entre os polos materialista e pós-materialista.

Para cada um dos países, foram consultadas e compiladas as respostas de dois a três especialistas, escolhidos com base em seu conhecimento sobre os partidos e os sistemas partidários do respectivo país de especialização, independentemente da origem e da filiação institucional.

O número de especialistas por país não foi definido previamente, já que esteve dependente da disponibilidade de quem foi contatado, e não invalida o que foi obtido, considerando que, com 234 partidos ou alianças por classificar em cinco dimensões, não seria de se esperar que a maioria dos contatados se dispusesse a fazê-lo. No estudo de Coppedge (1997), com o qual a comparação é mais pertinente, porque havia a mesma dificuldade em relação à quantidade de partidos para classificar por país, foram cinco especialistas para a Argentina e seis para a Venezuela. Como um procedimento extra em nome da transparência, este trabalho optou por calcular e informar as taxas de resposta e sucesso, o que não é a regra em estudos que se apoiam na opinião de especialistas.

As respostas dos especialistas foram contrastadas entre si, para a obtenção de uma classificação única por partido em cada dimensão, e, posteriormente, comparadas com os resultados de Coppedge, como forma de identificar as principais variações. Apesar das críticas que podem ser feitas, ${ }^{2}$ o recurso à opinião de especialistas para mensurar posições de par${ }^{2}$ Ver Mair (2001) para acessar um apanhado delas. tidos e classificá-los continua sendo utilizado e defendido na literatura. Para Benoit e Laver (2006), posições políticas são conceitos que não podem ser observados diretamente, fazendo com que qualquer método para estimá-las só tenha capacidade de apreender algumas de suas manifestações empíricas.

No caso dos partidos argentinos, é comum a avaliação de que classificá-los ideologicamente é um esforço desnecessário, por causa das peculiaridades e da conhecida incoerência ideológica. Esse argumento, porém, poderia ser estendido a um sem número de sistemas partidários ao redor do mundo, o que, em última análise, faria com que todo esforço de classificação ideológica fosse irrelevante. Não é o que se considera aqui, seja para o caso argentino, apesar de todas as dificuldades e as restrições que ele impõe, seja para outros, assim como não é o que consideram os estudos que este trabalho utilizou para obter dados sobre os partidos de Argentina e Venezuela.

\section{REVISÃO DA LITERATURA}

Em primeiro lugar, é importante salientar que não se fez uma revisão extensiva da literatura sobre partidos da Argentina e da Venezuela, optando-se por fazer uma compilação de trabalhos que, com diferentes fontes, métodos e objetivos, classificam as forças políticas de um e ambos os países como parte de uma análise geral sobre os partidos latino-americanos.

Rosas e Zechmeister (2000), Alcántara e Rivas (2007) e Alcántara (2012) utilizam uma escala que vai de 1 a 10 , considerando a esquerda como 1 e a direita como 10, para classificar os partidos latino-americanos com base em diferentes fontes e métodos. Wiesehomeier e Benoit (2007) também se valem de uma escala para a mesma finalidade, mas com um intervalo que vai de 1 a 20 , considerando a esquerda como 1 e a direita como 20. Por sua vez, Rosas e Zechmeister (2000) empregam a análise fatorial para construir sua escala com base nas 
entrevistas a legisladores que foram realizadas na rodada de 1997 do Proyecto Élites Parlamentarias Latinoamericanas, da Universidad de Salamanca. Há classificações para partidos tanto da Argentina quanto da Venezuela.

No caso argentino, entre os partidos classificados, quatro foram listados no trabalho, os três principais na época: Frente País Solidário (FREPASO), Partido Justicialista (PJ), União Cívica Radical (UCR) e a União do Centro Democrático (UCEDE). As pontuações recebidas foram, respectivamente, 3.50, 5.24, 4.53 e 8.00, com uma média de 5.32 .

Da Venezuela, foram cinco os partidos listados: quatro tradicionais, Ação Democrática (AD), COPEI, A Causa Radical (LCR) e Movimento ao Socialismo (MAS); e a Convergência, que governava o país no momento em que as entrevistas foram realizadas. Os cinco obtiveram, respectivamente, os valores de 4.50, 5.75, $4.60,3.67$ e 4.71 , com uma média de 4.65 , à esquerda, portanto, da média para os quatro partidos argentinos.

A escala de Alcántara e Rivas (2007) se baseia nas médias das pontuações atribuídas a seus partidos pelos legisladores participantes das rodadas de entrevistas do Proyecto Élites Parlamentarias Latinoamericanas entre 1997 e 2005. Também há classificações para forças políticas tanto da Argentina quanto da Venei. zuela, referentes a duas legislaturas. Portanto, $\stackrel{\circ}{\infty} 0$ os partidos argentinos classificados e listados no artigo citado foram o PJ e a UCR, que ficaram, respectivamente, com as pontuações médias de 5.50 e 4.88 na primeira legislatura e de 5.15 e 4.54 na segunda. Os valores para a pri$\dot{s}$ meira legislatura podem ser comparados com os de Rosas e Zechmeister (2000), já que se referem ao mesmo período, e foram ligeiramente superiores, mas ainda nos mesmos espaços da escala esquerda-direita, entre 5 e 6 para o PJ e entre 4 e 5 para a UCR.

No caso venezuelano, os partidos classificados e listados foram AD, COPEI e MAS, com as pontuações respectivas de 4.53, 5.67 e 4.13 na primeira legislatura, e de 5.60, 7.00 e
3.83 na segunda. Fazendo a mesma comparação dos valores para a primeira legislatura com os de Rosas e Zechmeister (2000), a única força que muda de espaço ocupado na escala é o MAS, que está mais à esquerda para os dois últimos autores, entre 3 e 4.

Alcántara (2012) utiliza as rodadas de entrevistas do Proyecto Élites Parlamentarias Latinoamericanas para verificar a variação nas localizações ideológicas dos partidos da região ao longo do tempo. Não são apresentadas classificações para as forças políticas da Venezuela. Portanto, da Argentina, foram listados Coalizão Cívica (CC), PJ, Proposta Republicana (PRO), Partido Socialista (PS) e UCR. Os dois partidos tradicionais, PJ e UCR, foram os únicos classificados nas cinco rodadas consideradas, que, para o caso argentino, foram realizadas em 1996, 1998, 2004, 2008 e 2010. A CC, o PRO e o PS só aparecem nas duas últimas edições.

O PJ foi da pontuação de 7.40 em 1996 à de 6.37 em 2010, mudando, então, de espaço na escala. Na rodada de 2008, os justicialistas chegaram a receber a pontuação de 4.79, o que mostra variação significativa de sua localização ao longo das cinco edições de entrevistas. Já a UCR foi de 5.63 a 6.35 , também mudando de espaço, embora sua variação, de uma rodada a outra ao longo das cinco edições de entrevistas, fosse menor. Enquanto isso, a CC, o PRO e o PS também variaram suas posições, em um período menor de tempo, entre 2008 e 2010, indo, respectivamente, de 4.15 a 6.02 , de 7.25 a 8.59 e de 4.14 a 3.71 . A variação mais significativa foi da CC, que passou do intervalo de 4 a 5 para o de 6 a 7 .

O trabalho de Wiesehomeier e Benoit (2007) é um banco de dados sobre a localização ideológica dos partidos latino-americanos, elaborado por meio da consulta a especialistas em cada país e com uma escala de 1 a 20 , como foi explicado anteriormente. Há classificações para forças políticas da Argentina e da Venezuela. No primeiro caso, os partidos, ou coligações que fazem parte do banco de dados são: Autodeterminação e Liberdade (3.16), CC 
(7.91), Frente Compromisso para a Mudança (16.24), Frente Popular Bonaerense (16.67), Movimento Popular Neuquino (15.89), PJ (12.12), PS (6.31), RECRIAR (União para Recriar Buenos Aires, 16.45) e UCR (9.18), com uma média de 11.55 .

Para a Venezuela, os partidos classificados são $\mathrm{AD}$ (11.35), COPEI (14.84), MAS (7.58), Partido Comunista da Venezuela (PCV, 2.10), Pela Democracia Social (PODEMOS, 4.67), Primeiro Justiça (PJ, 15.45), Pátria para Todos (PPT, 3.89), Partido Socialista Unificado da Venezuela ${ }^{3}$ (PSUV, 3.74) e Um Novo Tempo (UNT, 12.50), com uma média de 8.46, à esquerda, portanto, da que se obtém para a Argentina.

Existem, ainda, os autores Alcántara Sáez (2004) e Ramos Jiménez (1995), que utilizam categorias para, com base em diferentes fontes e métodos, fazer suas classificações. Alcántara Sáez (2004) parte de entrevistas com membros de partidos, realizadas no âmbito do Proyecto Élites Parlamentarias Latinoamericanas, em que os entrevistados localizam suas agrupações e as demais considerando 1 como esquerda e 10 como direita, divide a escala em cinco espaços iguais e classifica os partidos nas categorias de esquerda, centro-esquerda, centro, centro-direita e direita, conforme as posições que ocupam. Há classificações para forças políticas da Argentina e da Venezuela.

Do primeiro país, a FREPASO foi classificada como centro-esquerda, segundo a autolocalização e a dos outros, o PJ como centro e centro-direita, e a UCR como centro-esquerda e centro. Aos olhos dos outros partidos, então, tanto o PJ quanto a UCR estão à direita de suas próprias avaliações.

Já a Venezuela teve a $\mathrm{AD}$ classificada como centro e centro-direita, também de acordo com a autolocalização e a dos outros, o COPEI como centro-direita e direita, o MAS como

${ }^{3}$ O PSUV é a continuidade do Movimento Quinta República (MVR), o partido que Hugo Chávez fundou para disputar sua primeira eleição presidencial, em 1998. Conforme o ano do trabalho, a classificação se refere ao MVR ou ao PSUV. Para facilitar, será adotado o PSUV como padrão. centro-esquerda e centro, o PSUV como centro-esquerda e o Projeto Venezuela como centro-direita e direita. O PSUV, então, é o único que tem a mesma classificação para seus membros e os dos demais partidos e não está, na avaliação dos outros, à direita da própria.

Ramos Jiménez (1995) identifica 14 possibilidades do que define como famílias políticas e as emprega para fazer suas classificações, que incluem forças políticas da Argentina e da Venezuela. O autor classifica diversos partidos dos dois países, tanto tradicionais quanto novatos em relação à época em que escreve. Os considerados aqui são os que elegeram ao menos um representante para a Câmara Baixa desde as redemocratizações.

Da Argentina, o Partido Democrata-Cristão (PDC) foi classificado como democrata-cristão, o Partido Democrata Progressista (PDP) como radical, o Partido Intransigente (PI) como radical, o Partido Obreiro (PO) como extrema-esquerda, o Partido Socialista Autêntico (PSA) como socialista, o Partido Socialista Popular (PSP) como socialdemocrata, o PJ como populista, a UCEDE como neoconservadora, e a UCR como radical.

No caso da Venezuela, as classificações foram de socialdemocrata para a AD, democrata-cristão para Convergência e COPEI, neoliberal para Fórmula Um (F-1) e Nova Geração Democrática (NGD), socialista para o MAS e o Movimento Eleitoral do Povo (MEP), nacionalista para a Nova Alternativa (NA) e a União Republicana Democrática (URD), neoconservadora para a Organização Renovadora Autêntica (ORA) e comunista para o PCV.

Os quadros a seguir reúnem as classificações de todas as autoras e os autores, seja em escalas de 1 a 10 ou de 1 a 20 , ou em categorias.

As classificações propostas neste trabalho complementam e atualizam as dos autores reunidos nos quadros anteriores, assim como as de Coppedge (1997). Há, pelo menos, três razões para isso: 1) a abrangência das amostras, com todos os partidos que elegeram ao 
Quadro 1 - Classificações dos partidos argentinos na literatura

\begin{tabular}{|c|c|c|c|c|c|c|c|c|c|c|c|c|}
\hline \multirow[b]{2}{*}{$\begin{array}{c}\text { PARTIDO } \\
\text { OU } \\
\text { ALIANÇA }\end{array}$} & \multicolumn{12}{|c|}{ AUTORES } \\
\hline & 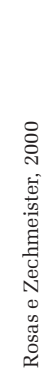 & 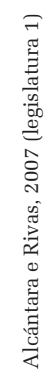 & 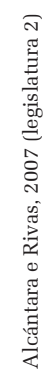 & 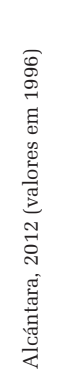 & 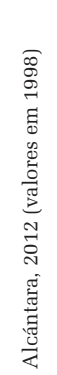 & 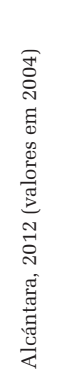 & 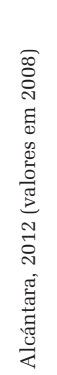 & 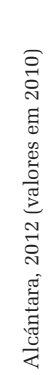 & 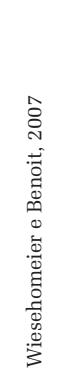 & 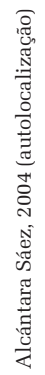 & 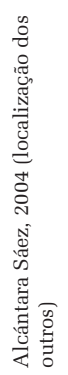 & 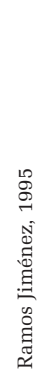 \\
\hline Aut. e Lib. & & & & & & & & & 3.16 & & & \\
\hline CC & & & & & & & 4.15 & 6.02 & 7.91 & & & \\
\hline Fr. Co. Mu. & & & & & & & & & 16.24 & & & \\
\hline Fr. Po. Bo. & & & & & & & & & 16.67 & & & \\
\hline FREPASO & 3.50 & & & & & & & & & $\mathrm{CE}$ & $\mathrm{CE}$ & \\
\hline Mo. Po. Ne. & & & & & & & & & 15.89 & & & \\
\hline PDC & & & & & & & & & & & & DC \\
\hline PDP & & & & & & & & & & & & RA \\
\hline PI & & & & & & & & & & & & RA \\
\hline PJ & 5.24 & 5.50 & 5.15 & 7.40 & 7.78 & 6.56 & 4.79 & 6.37 & 12.12 & C & $\mathrm{CD}$ & PP \\
\hline PO & & & & & & & & & & & & $\mathrm{EE}$ \\
\hline PRO & & & & & & & 7.25 & 8.59 & & & & \\
\hline PS & & & & & & & 4.14 & 3.71 & 6.31 & & & \\
\hline PSA & & & & & & & & & & & & so \\
\hline PSP & & & & & & & & & & & & SD \\
\hline RECRIAR & & & & & & & & & 16.45 & & & \\
\hline UCEDE & 8.00 & & & & & & & & & & & $\mathrm{NC}$ \\
\hline UCR & 4.53 & 4.88 & 4.54 & 5.63 & 5.57 & 5.79 & 6.06 & 6.35 & 9.18 & CE & C & RA \\
\hline
\end{tabular}

Fonte: Elaborado pelo autor (2016).

Aut. e Lib.: Autodeterminação e Liberdade; Fr. Co. Mu.: Frente Compromisso para a Mudança; Fr. Po. Bo.: Frente Popular Bonaerense; Mo. Po. Ne.: Movimento Popular Neuquino. CE: centro-esquerda; C: centro; CD: centro-direita. DC: democrata-cristão; EE: extrema-esquerda; NC: neoconservador; NL: neoliberal; PP: populista; RA: radical; SD: socialdemocrata; SO: socialista.

$\stackrel{\infty}{\circ}$

$\stackrel{\circ}{0}$

menos um representante para a Câmara Baixa nos pleitos entre 1983 e 2013 na Argentina e 1959 e 2010 na Venezuela; 2) a inclusão de par-

co

(ู)

文

prévia; e 3) a utilização de cinco dimensões de

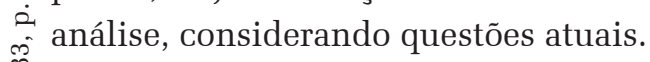

வ $\quad$ Em relação ao terceiro ponto, dois temas ì agregados, programático ou clientelista e apelo

$\dot{*}$ eleitoral étnico, são especialmente relevantes na América Latina, conforme foi explicado no 苗 item anterior. Com as classificações propostas, تَ é possível ir além da posição no eixo esquerd da e direita, oferecendo mais parâmetros para estudar os partidos de Argentina e Venezuela U ou utilizar as etiquetas de cristão ou secular, programático ou clientelista, materialista ou pós-materialista e presença ou não de apelo eleitoral étnico como explicações para o comportamento partidário ou de outras variáveis.

Para os sistemas partidários de Argentina e Venezuela, nas últimas duas décadas completas que foram consideradas aqui, as de 1990 e 2000, a literatura identificou crises de credibilidade de partidos e políticos, ao longo dos anos 1990, no caso venezuelano (Hellinger, 2003; Maingon, 2004), e ao início da década seguinte, no argentino (Abal Medina; Ratto, 2004; Escolar et al., 2002; Mustapic, 2002; Novaro, 2002).

Na Venezuela, foi o período em que o primeiro presidente que não fosse de $\mathrm{AD}$ nem 
Quadro 2 - Classificações dos partidos venezuelanos na literatura

\begin{tabular}{|c|c|c|c|c|c|c|c|}
\hline \multirow[b]{2}{*}{ PARTIDO } & \multicolumn{7}{|c|}{ Autores } \\
\hline & 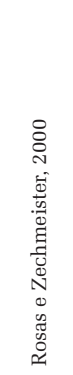 & 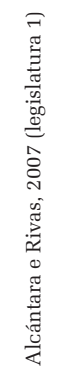 & 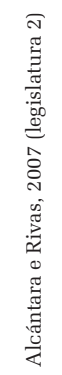 & 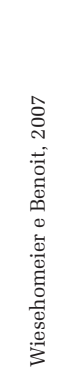 & 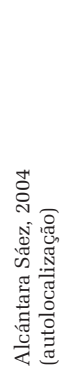 & 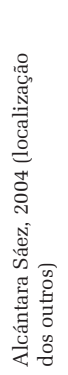 & 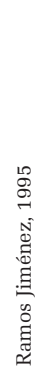 \\
\hline $\mathrm{AD}$ & 4.50 & 4.53 & 5.60 & 11.35 & C & $\mathrm{CD}$ & SD \\
\hline Convergência & 4.71 & & & & & & DC \\
\hline COPEI & 5.75 & 5.67 & 7.00 & 14.84 & $\mathrm{CD}$ & $\mathrm{D}$ & DC \\
\hline $\mathrm{F}-1$ & & & & & & & $\mathrm{NL}$ \\
\hline LCR & 4.60 & & & & & & \\
\hline MAS & 3.67 & 4.13 & 3.83 & 7.58 & $\mathrm{CE}$ & C & So \\
\hline MEP & & & & & & & So \\
\hline $\mathrm{NA}$ & & & & & & & $\mathrm{NN}$ \\
\hline NGD & & & & & & & $\mathrm{NL}$ \\
\hline ORA & & & & & & & $\mathrm{NC}$ \\
\hline PCV & & & & 2.10 & & & $\mathrm{CO}$ \\
\hline PSUV & & & & 3.74 & $\mathrm{CE}$ & $\mathrm{CE}$ & \\
\hline PPT & & & & 3.89 & & & \\
\hline PODEMOS & & & & 4.67 & & & \\
\hline PJ & & & & 15.45 & & & \\
\hline Projeto Venezuela & & & & & CD & $\mathrm{D}$ & \\
\hline UNT & & & & 12.50 & & & \\
\hline URD & & & & & & & $\mathrm{NN}$ \\
\hline
\end{tabular}

COPEI se elegeu desde 1958, com a vitória, em ardo Duhalde, do PJ, eleito pelo Congresso, as1993, de Rafael Caldera, candidato pelo partisumiu a Presidência, permanecendo até 2003. do recém-criado, Convergência. Caldera vinha As ascensões de Chávez em 1999 e Néstor do COPEI e havia obtido um primeiro mandato por esse partido em 1968. A ruptura com a lógica bipartidária na disputa presidencial se completaria, então, na eleição seguinte, em 1998, com a vitória de Hugo Chávez por outro partido, novato à época, o então MVR.

Na Argentina, o início dos anos 2000 foi o período do "Que se Vayan Todos", em que, sob manifestações violentas nas ruas, quatro presidentes se sucederam ao longo de cerca de 10 dias, entre 21 de dezembro de 2001, quando Fernando de la Rúa, da UCR, eleito em 1999, renunciou, e 2 de janeiro de 2002, quando EduKirchner em 2003 levaram ao poder propostas de enfretamento das crises de credibilidade política e de grupos que os dois presidentes consideravam que haviam contribuído para elas, o que, em maior ou menor medida, promoveu conflito e polarização, no cenário político, em torno de suas figuras e da concordância ou não com os projetos políticos que representavam (Canache, 2004; Cannon, 2008; Cheresky, 2004; Ellner; Hellinger, 2003; Heath, 2009; Hellinger, 2007; López Maya, 2003; López Maya; Lander, 2007; Roberts, 2003). No caso de Kirchner, chegou a haver um primeiro momento de aglutina- 
ção de forças, a "transversalidad", assim como Chávez teve o seu, mas que se dissiparam com mais ou menos rapidez, até pela longevidade de ambos os projetos no poder, já que foram três mandatos seguidos do kirchnerismo (2003 2015) e quatro do chavismo (1999 - ).

\section{SURVEY COM ESPECIALISTAS}

$\mathrm{Na}$ avaliação dos partidos argentinos, foi enviado um e-mail para 13 especialistas convidando-os a participar. Desses, três enviaram suas classificações, dois concordaram em participar e não enviaram as avaliações, cinco recusaram o convite, e três não responderam, o que significa taxas de sucesso e resposta de, respectivamente, 23,08\% e 76,92\%.

Para a Venezuela, os percentuais foram mais baixos, o que levou a se aumentar o número de tentativas. O convite foi enviado a 29 especialistas. Dois, finalmente, enviaram suas classificações. Dos demais, cinco concordaram em participar e não enviaram as avaliações, sete recusaram o convite e 15 não responderam. Com isso, as taxas de sucesso e resposta foram de, respectivamente, $6,90 \%$ e 48,27\%. Foi pedido aos especialistas que classificassem em cinco dimensões todos os partidos que ele-

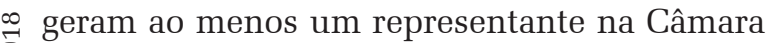
Baixa de seu respectivo país desde a redemocratização até a última eleição antes do início do envio dos questionários.

Da Argentina, foram as edições de 1983 a 2013, totalizando 16 eleições para deputado, já que elas são realizadas a cada dois anos. Quando foi o caso, foram incluídos partidos ou alianças que, apesar de não terem eleito representante em 2011 e 2013, compunham a Câmara Baixa até 2015. A última eleição para a casa, justamente a de 2015, não pôde ser considerada porque foi realizada depois do início da distribuição dos questionários aos especialistas. Com esses procedimentos, houve um total de 183 partidos ou alianças para classificar. A Venezuela, mais uma vez, teve núme- ros menores, tanto de eleições consideradas quanto de partidos com ao menos um representante eleito. As edições computadas foram as de 1963 a 2010, totalizando 11 eleições para deputado, já que elas são realizadas a cada cinco anos. Em 2000, com a aprovação de uma nova Constituição no ano anterior, a contagem do intervalo recomeçou. A última eleição para a Câmara Baixa, então, foi em 2015, mas ela não pôde ser considerada porque foi realizada depois que os questionários começaram a ser enviados aos especialistas. Um total de 51 partidos elegeu, pelo menos, um representante no período considerado.

As cinco dimensões compreendem as duas originais de Coppedge (1997) - esquerda ou direita, e cristão ou secular - e as três acrescidas - programático ou clientelista, materialista ou pós-materialista, e apelo eleitoral étnico. Cada uma dessas dimensões tem suas categorias, com as respectivas definições. As duas primeiras são tratadas em conjunto por Coppedge. Dessa forma, suas categorias são XR (direita cristã), XCR (centro-direita cristã), XC (centro cristão), XCL (centro-esquerda cristã), XL (esquerda cristã), SR (direita secular), SCR (centro-direita secular), SC (centro secular), SCL (centro-esquerda secular) e SL (esquerda secular). Há, ain$\mathrm{da}$, as categorias residuais de $\mathrm{O}$ (outro bloco), $\mathrm{P}$ (personalista) e U (desconhecido).

Os partidos cristãos são aqueles que alegam basear sua ideologia na autoridade da Igreja Católica, na Bíblia ou em crença religiosa, que defendem os interesses da Igreja Católica ou rejeitam ou buscam reduzir a separação entre igreja e Estado, ou que, na percepção geral, satisfazem um dos critérios, ainda que a religião não seja mais um aspecto importante de seu programa. Os partidos seculares, por sua vez, são os que não se baseiam na autoridade da Igreja Católica, na Bíblia ou em crença religiosa, ou que desafiam os interesses da Igreja Católica, ou ainda apoiam a separação entre igreja e Estado.

A etiqueta de direita abrange os partidos que têm como público-alvo os herdeiros da eli- 
te tradicional do século XIX e não moderam seu discurso para atrair eleitores das classes média e baixa; que adotam uma ideologia fascista ou neofascista; ou que representam um regime militar vigente ou passado, desde que tenham um programa conservador e não sejam unicamente um veículo personalista de líderes autoritários. As forças de centro-direita, por outro lado, são as que buscam agregar ao seu eleitorado de elite os votos das classes média e baixa, defendendo a cooperação com o setor privado, a ordem, um governo enxuto, a moralidade ou a prioridade ao crescimento econômico em detrimento da distribuição de renda.

No centro do espectro ideológico, estão os partidos que enfatizam aspectos do liberalismo político clássico, como participação política ampla, consciência cívica, império da lei, direitos humanos ou democracia, sem uma agenda social ou econômica proeminente; ou que adotam políticas de governo tão divididas entre posições de esquerda e direita, que não é possível discernir uma orientação consistente de uma eleição a outra.

A etiqueta de esquerda abrange os partidos que adotam uma ideologia ou retórica marxista, enfatizam a prioridade da distribuição de renda em detrimento da acumulação e (ou) exploração da classe trabalhadora pelos capitalistas e imperialistas e defendem um papel ativo do Estado para corrigir as injustiças sociais e econômicas. Essas forças podem considerar a violência como uma forma apropriada de disputa política e não se preocupam em alienar os eleitores das classes média e alta. Os partidos de centro-esquerda, por outro lado, enfatizam a justiça, a igualdade e a mobilidade sociais ou a complementariedade entre distribuição e acumulação de renda de uma forma que não aliene os eleitores das classes média e alta.

Para finalizar as definições de Coppedge (1997), restam as categorias de outro bloco, personalista e desconhecido. Na primeira, está qualquer partido que represente uma ideologia, programa, princípio, região, interesse ou grupo que seja identificável e não possa ser classificada em termos de esquerda-direita ou cristão-secular. Já a etiqueta de personalista abrange as forças que têm como principal apelo o carisma, a autoridade ou a competência de seu líder mais do que quaisquer princípios ou programas, que são tão vagos ou inconsistentes para permitir uma classificação plausível do partido de alguma outra forma; que são plataformas eleitorais para a inscrição de candidatos independentes; ou que são frentes heterogêneas formadas para apoiar um candidato.

A última categoria residual, desconhecido, serve para os partidos sobre os quais a única informação disponível é o nome, que tampouco fornecem pistas confiáveis sobre sua orientação. Certas palavras presentes nos nomes, como "comunista" e "esquerda", podem ser indicadores confiáveis. Outras tantas, como "revolucionário", "socialista”, "democrata”, "liberal”, "trabalhista”, "popular” e "republicano” não são.

As dimensões que foram agregadas às de Coppedge também contam com categorias e suas respectivas definições. Na dimensão de programático ou clientelista, as possibilidades são P (programático), PC (combinação de programático e clientelista), C (clientelista) e NS (não sabe). Os partidos que se enquadram na primeira categoria são os que propõem e (ou) oferecem políticas públicas formais dirigidas a setores populacionais em troca de votos. As forças clientelistas, por outro lado, são as que trocam, de forma mais sistemática e direta, incentivos seletivos materiais por votos.

Na dimensão de materialista ou pós-materialista, as possibilidades são M (materialista), MPM (combinação de materialista e pós-materialista), PM (pós-materialista) e NS (não sabe). Os partidos que se ajustam à primeira categoria são os que enfatizam temas clássicos de direita ou esquerda, que marcaram a segunda metade do século XX, como capitalismo versus socialismo, ou liberalismo versus Estado de bem-estar. As forças pós-materialistas, por outro lado, são as que enfatizam temas relacionados à autoexpressão individual 
ou coletiva e à qualidade de vida, como ecologia, feminismo, identidade cultura e direitos de minorias.

Por fim, na dimensão de apelo eleitoral étnico, as opções são 1 (incorpora apelo eleitoral étnico), 0 (não incorpora) e NS (não sabe). Os partidos que têm apelo eleitoral étnico são aqueles cuja maioria dos líderes e membros se reconhecem como parte de um grupo étnico e cuja plataforma eleitoral inclui demandas de natureza étnica ou cultural.

Começando pela Argentina e considerando as forças políticas que receberam ao menos duas classificações, nas dimensões esquerda-direita e secular-cristão, e também foram classificadas por Coppedge (1997), houve mais casos de manutenção de categoria do que de variação. Nesse grupo de 17, já que a grande maioria dos 183 partidos ou alianças não teve pelo menos duas classificações ou não foi classificada por Coppedge, foram 9 casos de manutenção de categoria, 4 de variação e 4 indefinidos, situação em que a discordância entre os especialistas consultados não permitiu que se obtivesse uma classificação única para ser comparada com a de Coppedge.

Os partidos que não variaram foram: Aliança de Centro (SCR), Aliança Esquerda Unida (SL), FREPASO (SCL), MODIN (Mo$\stackrel{\infty}{\sim}$ vimento pela Dignidade e pela Independência, SR), Movimento Popular Jujenho (O), PI (SCL), PO (SL), PS (SCL) e UCR (SC). As variações, por sua vez, foram de Frente Renovadora (de O para SC), Força Republicana (de SCR para SR), PJ (de O para SC) e UCEDE (de SCR para SR). E os indefinidos, seguidos da respectiva classificação que obtiveram de Coppedge entre parênteses, foram: Movimento Popular Neuquino (P), PH (Partido Humanista, O), Partido Renovador de Salta (O) e UCR - Intransigente (SC).

Se considerarmos só os principais partidos de abrangência nacional no grupo acima, independentemente de quando foram mais votados, o número de manutenções de categoria também é maior do que o de variações. Na pri- meira situação, estão FREPASO, PI, PS e UCR, e, na segunda, PJ e UCEDE. Há, ainda, partidos ou alianças que surgiram ou elegeram representante para a Câmara Baixa depois do artigo de Coppedge e receberam dos especialistas consultados por este trabalho ao menos duas classificações nas dimensões esquerda-direita e secular-cristão. Os casos mais importantes, seguidos da sua classificação, foram: CC (SCL); Compromisso Federal (P); Frente Renovadora, a de Sergio Massa (SC); PJ - Frente para a Vitória (SCL); e PRO (SCR).

Nas outras três dimensões, de programático ou clientelista, materialista ou pós-materialista e apelo eleitoral étnico, o número de partidos ou alianças classificados pelos especialistas se reduziu. Os que receberam ao menos duas classificações por dimensão foram: Aliança de Centro (P, M e 0); CC (P, indefinido e 0); Frente Renovadora (indefinido, $\mathrm{M}$ e 0); Frente Renovadora, a de Massa (indefinido, M e 0); FREPASO (P, indefinido e 0); MODIN (PC, $\mathrm{M}$ e 0); Movimento Popular Neuquino (C, M e 0); PJ (PC, $\mathrm{M}$ e 0), assim como suas facções Frente Justicialista, Frente Justicialista para a Vitória e Frente para a Vitória; PH (P, PM e 0); $\mathrm{PO}$ (P, $\mathrm{M}$ e 0); PRO (indefinido, indefinido e 0 ), assim como suas facções Frente Democrata, Frente União PRO Dignidade, Santa Fé Federal e União PRO; e UCEDE (P, M e 0).

Só então o Movimento Popular Neuquino e o PH foram classificados por ao menos dois especialistas como, respectivamente, clientelista e pós-materialista. O PJ e três das suas facções e o MODIN foram considerados como uma combinação de programático e clientelista. Não houve partido que tenha sido classificado como de apelo eleitoral étnico. Dando sequência, os quadros a seguir reúnem as classificações de Coppedge (1997) e dos especialistas consultados por este trabalho, referentes aos partidos ou às alianças que receberam pelo menos duas avaliações em todas as dimensões. A lista completa das classificações feitas por cada especialista pode ser consultada no Anexo. 
Quadro 3 - Classificações dos partidos argentinos nas dimensões esquerda-direita e secular-cristão

\begin{tabular}{|c|c|c|c|c|c|}
\hline \multirow[b]{2}{*}{ PARTIDO OU ALIANÇA } & \multicolumn{5}{|c|}{ ESPECIALISTAS } \\
\hline & 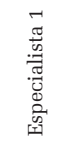 & 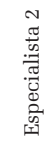 & 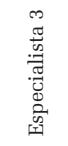 & $\begin{array}{l}\overline{\mathbb{G}} \\
\text { Uु }\end{array}$ & 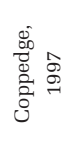 \\
\hline Aliança de Centro & SR & SCR & SCR & SCR & SCR \\
\hline $\mathrm{CC}$ & SCL & SC & SCL & SCL & - \\
\hline Frente Renovadora & SC & - & SC & SC & $\mathrm{O}$ \\
\hline Frente Renovadora (Massa) & $\mathrm{SC}$ & $\mathrm{P}$ & SC & SC & - \\
\hline FREPASO & SCL & SCL & SCL & SCL & SCL \\
\hline MODIN & SR & SR & SR & SR & SR \\
\hline Movimento Popular Neuquino & SC & $\mathrm{O}$ & SCR & Indef. & $\mathrm{P}$ \\
\hline $\mathrm{PH}$ & SC & - & SCL & Indef. & $\mathrm{O}$ \\
\hline PJ & SC & $\mathrm{O}$ & SC & SC & $\mathrm{O}$ \\
\hline PJ - Frente para a Vitória & SCL & - & SCL & SCL & - \\
\hline $\mathrm{PO}$ & SL & SL & SL & SL & SL \\
\hline PRO & SCR & - & SCR & SCR & - \\
\hline UCEDE & SR & SCR & SR & SR & SCR \\
\hline $\mathrm{UCR}^{*}$ & SC & SC & SC & SC & SC \\
\hline
\end{tabular}

Fonte: survey com especialistas (2016).

Indef.: indefinido; O: outro bloco; P: personalista; SC: centro secular; SCL: centro-esquerda secular; SCR: centro-direita secular; SL: esquerda secular; SR: direita secular.

* A UCR não recebeu pelo menos duas classificações em todas as cinco dimensões, mas foi incluída no quadro por causa de sua importância histórica. A única dimensão em que não houve o mínimo de classificações foi a de programático ou clientelista.

Quadro 4 - Classificações dos partidos argentinos nas dimensões de programático ou clientelista, materialista ou pós-materialista e apelo eleitoral étnico

\begin{tabular}{|c|c|c|c|c|c|c|c|c|c|c|c|c|}
\hline \multirow[b]{3}{*}{ PARTIDO OU ALIANÇA } & \multicolumn{12}{|c|}{ ESPECIALISTAS } \\
\hline & \multicolumn{3}{|c|}{ Especialista 1} & \multicolumn{3}{|c|}{ Especialista 2} & \multicolumn{3}{|c|}{ Especialista 3} & \multicolumn{3}{|c|}{ Geral } \\
\hline & 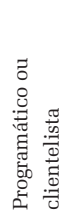 & 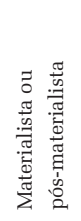 & 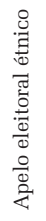 & 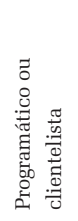 & 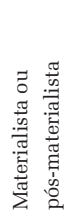 & 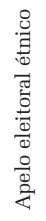 & 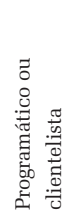 & 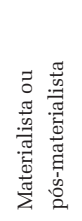 & 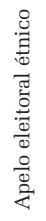 & 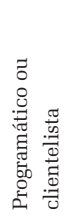 & 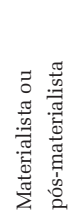 & 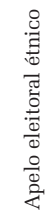 \\
\hline Aliança de Centro & $\mathrm{P}$ & M & 0 & $\mathrm{P}$ & - & - & - & M & 0 & $\mathrm{P}$ & M & 0 \\
\hline CC & $\mathrm{P}$ & M & 0 & $\mathrm{P}$ & - & - & - & $\mathrm{PM}$ & 0 & $\mathrm{P}$ & Ind. & 0 \\
\hline Frente Renovadora & PC & M & 0 & - & - & - & $\mathrm{C}$ & M & 0 & Ind. & M & 0 \\
\hline Frente Renovadora (Massa) & PC & M & 0 & - & - & - & $\mathrm{C}$ & M & 0 & Ind. & M & 0 \\
\hline FREPASO & $\mathrm{P}$ & M & 0 & $\mathrm{P}$ & - & - & $\mathrm{P}$ & MPM & 0 & $\mathrm{P}$ & Ind. & 0 \\
\hline MODIN & PC & M & 0 & $\mathrm{P}$ & - & - & PC & M & 0 & PC & M & 0 \\
\hline $\begin{array}{l}\text { Movimento Popular } \\
\text { Neuquino }\end{array}$ & $\mathrm{C}$ & M & 0 & - & - & - & $\mathrm{C}$ & M & 0 & $\mathrm{C}$ & M & 0 \\
\hline $\mathrm{PH}$ & $\mathrm{P}$ & M & 0 & $\mathrm{P}$ & $\mathrm{PM}$ & - & - & $\mathrm{PM}$ & 0 & $\mathrm{P}$ & $\mathrm{PM}$ & 0 \\
\hline PJ & PC & M & 0 & - & - & - & $\mathrm{PC}$ & $\mathrm{M}$ & 0 & PC & $\mathrm{M}$ & 0 \\
\hline PJ - Frente para a Vitória & PC & M & 0 & - & - & - & $\mathrm{PC}$ & M & 0 & PC & $\mathrm{M}$ & 0 \\
\hline $\mathrm{PO}$ & $\mathrm{P}$ & M & 0 & $\mathrm{P}$ & - & - & $\mathrm{P}$ & M & 0 & $\mathrm{P}$ & M & 0 \\
\hline PRO & PC & M & 0 & - & - & - & $\mathrm{P}$ & PM & 0 & Ind. & Ind. & 0 \\
\hline UCEDE & $\mathrm{P}$ & $\mathrm{M}$ & 0 & $\mathrm{P}$ & - & - & $\mathrm{P}$ & $\mathrm{M}$ & 0 & $\mathrm{P}$ & $\mathrm{M}$ & 0 \\
\hline $\mathrm{UCR}^{*}$ & PC & M & 0 & - & - & - & - & MPM & 0 & PC & Ind. & 0 \\
\hline
\end{tabular}


Para a Venezuela, considerando o conjunto de forças políticas que receberam pelo menos duas classificações nas dimensões esquerda-direita e secular-cristão e, ao mesmo tempo, foram classificadas por Coppedge (1997), também houve mais casos de manutenção de categoria do que de variação. Foram 7 os que cumpriram esses dois requisitos, já que a grande maioria dos 51 partidos não obteve ao menos duas classificações, ou não foi classificada por Coppedge. Desses 7, foram 5 casos de manutenção de categoria e 2 de variação. Não houve situações de indefinição, porque, como foram dois especialistas que fizeram as avaliações, foi necessário que se fizesse um desempate para que não fosse muito pequeno o número de casos com uma classificação única que pudesse ser comparada com a de Coppedge.

Os que não variaram são COPEI (XCR), LCR (SCL), MAS (SCL), ORA (XCR) e PCV (SL). Já as variações foram de AD (de SCL para SC) e MDP-BR (Movimento Democrático Popular - Bandeira Vermelha, de U para SL). Se considerarmos apenas os principais partidos, o número de manutenções de categoria continua sendo maior do que o de variações, com COPEI, LCR, MAS e PCV na primeira situação e $\mathrm{AD}$ na segunda.

Há ainda os partidos que surgiram ou ๘ elegeram representante para a Câmara Baixa N. depois do artigo de Coppedge e receberam dos $\stackrel{\circ}{\&}$ especialistas consultados ao menos duas classificações nas dimensões esquerda-direita e secular-cristão. Os casos, seguidos da respectiva classificação, são: ABP (Aliança Bravo Povo, SR), CONIVE (Conselho Nacional Indígena $\dot{2}$ da Venezuela, SL), IRENE (P), MiGato (Movimento Independente Ganhamos Todos, P), PJ (SCR), PODEMOS (SCL), PPT (SL), Projeto Venezuela (XCR), PSUV (SL) e UNT (SCL).

Diferentemente da Argentina, três partidos venezuelanos do grupo dos que receberam ao menos duas avaliações foram classificados como cristãos, o COPEI, uma força política tradicional, a ORA, que elegeu representante pela última vez para a Câmara Baixa em 1998, e o
Projeto Venezuela, um partido mais recente, todos os três de centro-direita. Nas outras três dimensões, de programático ou clientelista, materialista ou pós-materialista e apelo eleitoral étnico, não houve casos de partidos com pelo menos duas avaliações, já que um dos especialistas praticamente não fez classificações para essas dimensões.

Os que receberam pelo menos uma classificação nas três dimensões foram: ABP (PC, $\mathrm{M}$ e 0), $\mathrm{AD}$ (PC, $\mathrm{M}$ e 0), CONIVE (P, PM e 1), COPEI (PC, M e 0), LCR (PC, M e 0), MAS (P, $\mathrm{M}$ e 0), MDP-BR (P, M e 0), MiGato (NS, M e 0), ORA (P, PM e 0), PCV (P, M e 0), PJ (PC, M e 0), PODEMOS (P, M e 0), PPT (P, M e 0), Projeto Venezuela (P, M e 0), PSUV (PC, M e 0) e UNT (P, M e 0). Houve, então, dois partidos classificados como pós-materialistas, o CONIVE e a ORA, e um como de apelo eleitoral étnico, o mesmo CONIVE. Nenhum foi avaliado como clientelista, enquanto ABP, AD, COPEI, LCR, PJ e PSUV foram classificados como uma combinação de programático e clientelista.

Os quadros 5 e 6 reúnem as classificações de Coppedge (1997) e dos especialistas consultados, referentes aos partidos que receberam pelo menos duas avaliações nas duas primeiras dimensões e uma nas três últimas. A lista completa das classificações feitas por cada especialista pode ser consultada no Anexo.

\section{CONCLUSÕES}

Como o artigo de Coppedge foi publicado em 1997, quando o processo de perda de legitimidade dos partidos tradicionais, na Argentina e na Venezuela, ainda não havia se acentuado, o que ocorreria entre o fim daquela década e o início dos anos 2000, as mudanças que puderam ser observadas desde então, nos sistemas partidários dos dois países, foram significativas. No entanto, no caso argentino, apesar da perda de legitimidade dos partidos tradicionais por causa da crise econômica e política do início dos anos 2000, essas mesmas 
Quadro 5 - Classificações dos partidos venezuelanos nas dimensões esquerda-direita e secular-cristão

\begin{tabular}{|c|c|c|c|c|}
\hline \multirow[b]{2}{*}{ PARTIDO } & \multicolumn{4}{|c|}{ ESPECIALISTAS } \\
\hline & 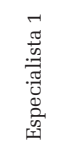 & 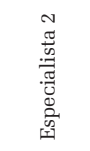 & 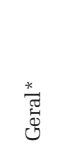 & 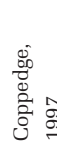 \\
\hline $\mathrm{ABP}$ & SR & SCL & SR & - \\
\hline $\mathrm{AD}$ & SCL & $\mathrm{SC} / \mathrm{SCR}$ & SC & SCL \\
\hline CONIVE & $\mathrm{O}$ & SL & SL & - \\
\hline COPEI & $\mathrm{XC}$ & XCR & XCR & XCR \\
\hline LCR & SCL & SCL & SCL & SCL \\
\hline MAS & SCL & SCL & SCL & SCL \\
\hline MDP-BR & SL & SL & SL & $\mathrm{U}$ \\
\hline MiGato & $\mathrm{U}$ & $\mathrm{P}$ & $\mathrm{P}$ & - \\
\hline ORA & $\mathrm{O}$ & XCR & XCR & $\mathrm{XCR}$ \\
\hline PCV & SCL & SL & SL & SL \\
\hline PJ & SC & SCR & SCR & - \\
\hline PODEMOS & SCL & SL & SCL & - \\
\hline PPT & SC & SL & SL & - \\
\hline Projeto Venezuela & SC & XCR & XCR & - \\
\hline PSUV & $\mathrm{P}$ & SL & SL & - \\
\hline UNT & SCL & SCL & SCL & - \\
\hline
\end{tabular}

Fonte: survey com especialistas (2016).

O: outro bloco; P: personalista; SC: centro secular; SCL: centro-esquerda secular; SCR: centro-direita secular; SL: esquerda secular; SR: direita secular; U: desconhecido; XC: centro cristão; XCR: centro-direita cristã.

* Quando necessário, o desempate foi feito pelo autor deste trabalho.

Quadro 6 - Classificações dos partidos venezuelanos nas dimensões de programático ou clientelista, materialista ou pós-materialista e apelo eleitoral étnico

\begin{tabular}{|c|c|c|c|c|c|c|c|c|c|}
\hline \multirow[b]{3}{*}{ PARTIDO } & \multicolumn{9}{|c|}{ ESPECIALISTAS } \\
\hline & \multicolumn{3}{|c|}{ Especialista 1} & \multicolumn{3}{|c|}{ Especialista 2} & \multicolumn{3}{|c|}{ Geral $^{*}$} \\
\hline & 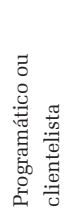 & 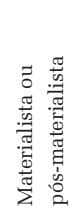 & 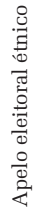 & 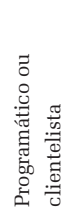 & 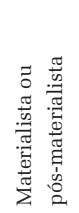 & 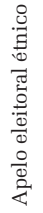 & 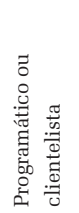 & 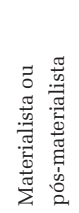 & 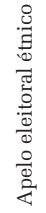 \\
\hline $\mathrm{ABP}$ & - & - & - & PC & M & 0 & PC & $\mathrm{M}$ & 0 \\
\hline $\mathrm{AD}$ & - & - & - & PC & M & 0 & PC & $\mathrm{M}$ & 0 \\
\hline CONIVE & - & - & - & $\mathrm{P}$ & PM & 1 & $\mathrm{P}$ & PM & 1 \\
\hline COPEI & - & - & - & PC & $\mathrm{M}$ & 0 & PC & $\mathrm{M}$ & 0 \\
\hline LCR & - & - & - & $\mathrm{P} / \mathrm{PC}$ & $\mathrm{M}$ & 0 & PC & $\mathrm{M}$ & 0 \\
\hline MAS & - & - & - & $\mathrm{P} / \mathrm{PC}$ & $\mathrm{M}$ & 0 & $\mathrm{P}$ & $\mathrm{M}$ & 0 \\
\hline MDP-BR & - & - & - & $\mathrm{P}$ & M & 0 & $\mathrm{P}$ & $\mathrm{M}$ & 0 \\
\hline MiGato & - & - & - & NS & $\mathrm{M}$ & 0 & NS & $\mathrm{M}$ & 0 \\
\hline ORA & - & - & - & $\mathrm{P}$ & PM & 0 & $\mathrm{P}$ & PM & 0 \\
\hline PCV & - & - & - & $P$ & M & 0 & $\mathrm{P}$ & $\mathrm{M}$ & 0 \\
\hline PJ & - & - & - & $\mathrm{P} / \mathrm{PC}$ & M & 0 & PC & $\mathrm{M}$ & 0 \\
\hline PODEMOS & - & - & - & $P$ & M & 0 & $\mathrm{P}$ & $\mathrm{M}$ & 0 \\
\hline PPT & - & - & - & $\mathrm{P}$ & M & 0 & $\mathrm{P}$ & $\mathrm{M}$ & 0 \\
\hline Projeto Venezuela & - & - & - & $\mathrm{P}$ & M & 0 & $\mathrm{P}$ & $\mathrm{M}$ & 0 \\
\hline PSUV & - & - & - & PC & $\mathrm{M}$ & 0 & $\mathrm{PC}$ & $\mathrm{M}$ & 0 \\
\hline UNT & - & - & - & $\mathrm{P}$ & M & 0 & $\mathrm{P}$ & $\mathrm{M}$ & 0 \\
\hline
\end{tabular}

Fonte: survey com especialistas (2016)

P: programático; PC: mescla de programático e clientelista; NS: não sabe; M: materialista; PM: pós-materialista; 1: apelo eleitoral étnico; 0: sem apelo eleitoral étnico.

* Quando necessário, o desempate foi feito pelo autor deste trabalho. 
forças conseguiram se recuperar eleitoralmente com mais ou menos rapidez, e receberam classificações que apresentam pouca variação em relação às de Coppedge.

Os principais partidos ou alianças representadas na Câmara Baixa até a realização das eleições de 2015 (CC; Compromisso Federal; Frente Renovadora, de Massa; PJ - Frente para a Vitória; PRO; PS; e UCR), que, juntos, controlavam $80,54 \%$ das 257 cadeiras, estão concentrados em torno do centro na dimensão esquerda-direita e são seculares. Desses, o único que não foi classificado como SCL, SC ou SCR é o Compromisso Federal, que, por sua vinculação aos irmãos Alberto e Adolfo Rodríguez Saá, foi avaliado como personalista.

Considerando esse mesmo grupo e ao menos duas classificações por dimensão, não há partido clientelista, pós-materialista ou com apelo eleitoral étnico. A Frente para a Vitória, que é a facção vinculada aos Kirchner no PJ, foi avaliada como uma combinação de programática e clientelista. Com base na opinião de um único especialista, são dois partidos ou alianças clientelistas, o Compromisso Federal e a Frente Renovadora vinculada a Massa, e dois pós-materialistas, a CC e o PRO.

A Venezuela, por sua vez, passou por uma transformação mais radical, já que os par-

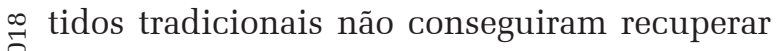
o predomínio anterior, ao mesmo tempo em \&ue forças surgiram e se tornaram dominantes, tanto do lado do governismo como do lado da oposição.

Os principais partidos representados na Câmara Baixa até a realização da última eleição em 2015 (AD, COPEI, LCR, PJ, PODEMOS, PPT, Projeto Venezuela, PSUV e UNT), que, juntos, conquistaram no pleito anterior 96,97\% das vagas, estão concentrados em torno do centro e são, na maioria dos casos, seculares. Porém o fato de que o PSUV, que detinha, sozinho, $58,18 \%$ das cadeiras e governa o país, tenha sido classificado como esquerda, assim como o PPT, faz com que se configure uma polarização ideológica, já que, dos seus principais opositores na época (AD, COPEI, PJ, Projeto Venezuela e UNT), só o UNT não está no centro ou na centro-direita. Na dimensão secular-cristão, há dois partidos entre as principais forças políticas até 2015 que foram classificados como cristãos, o COPEI e o Projeto Venezuela.

Considerando o mesmo grupo de nove partidos e pelo menos uma classificação por dimensão, nenhuma força foi avaliada como clientelista, pós-materialista ou de apelo eleitoral étnico. AD, COPEI, LCR, PJ e PSUV foram classificados como uma combinação de programático e clientelista.

De uma forma geral, os sistemas partidários da Argentina e da Venezuela transitaram da perda de legitimidade dos partidos tradicionais até o início da década de 2000 para cenários que se caracterizavam, no momento desta classificação, pela polarização em torno da adesão ou da oposição aos projetos políticos iniciados por, respectivamente, Néstor Kirchner em 2003 e Hugo Chávez em 1999. No caso argentino, tratava-se mais de uma polarização entre apoiar ou se opor ao governo de turno do que em termos ideológicos, já que os principais partidos estavam distribuídos em torno do centro. Na Venezuela, por sua vez, tratava-se de uma polarização em ambos os sentidos.

Também diferentemente do caso venezuelano, a oposição ao kirchnerismo, na Argentina, não se dava por meio da formação de um bloco oposicionista. Apesar das divergências, os partidos de oposição ao chavismo, na Venezuela, começaram a se articular na Coordenadora Democrática (CD) e disputaram a eleição legislativa de 2015 sob uma única sigla, a da MUD (Mesa de Unidade Democrática). A confrontação ao kirchnerismo nunca chegou a esse ponto, e foi, em si mesma, alvo de disputa acirrada, desde o próprio peronismo, por figuras como Eduardo Duhalde, os Rodríguez Saá e Sergio Massa, ao PRO. Por outro lado, na última eleição presidencial, em 2015, foi uma aliança oposicio- 
nista em torno da candidatura de Mauricio Macri, do PRO, reunindo seu partido, UCR e CC, que conseguiu tirar o kirchnerismo do poder.

Em termos dos principais partidos no momento da classificação, havia uma concentração em torno do centro, na Argentina, desde o centro-esquerda ao centro-direita, sem a presença de forças cristãs, clientelistas, pós-materialistas ou com apelo eleitoral étnico, que assim fossem classificadas por, ao menos, dois especialistas. É de chamar a atenção o fato de que, em um país utilizado na literatura como caso de estudo do clientelismo na América Latina (Amaral; Stokes, 2005; Stokes et al., 2013), nenhum dos sete partidos ou alianças mais importantes tenha sido avaliado como clientelista. Os que chegaram mais perto disso foram a Frente para a Vitória, partido classificado como uma combinação de programático e clientelista, e Compromisso Federal e Frente Renovadora, clientelistas para um especialista.

Do lado venezuelano, havia uma divisão de blocos ideológicos entre o chavismo, na esquerda, e a oposição de centro ou centro-direita, com dois partidos oposicionistas, COPEI e Projeto Venezuela, classificados como cristãos e nenhum, seja da situação ou da oposição, como clientelista, pós-materialista ou de apelo eleitoral étnico. Novamente, a ausência de forças clientelistas (cinco entre as principais foram avaliadas como uma combinação de programático e clientelista) chama a atenção, já que a Venezuela é outro caso de estudo do tema na literatura (Stokes et al., 2013). Também é de se notar a não existência de partido com apelo eleitoral étnico, considerando que, sob o chavismo, o tema tem sido abordado na legislação eleitoral e no discurso político.

Recebido para publicação em 27 de setembro 2016 Recebido em 16 de julho de 2018

\section{REFERÊNCIAS}

ABAL MEDINA, J. M.; RATTO, M. C. El sistema de representación después del "diluvio": hacia una relectura del esquema partidario argentino. In: INTERNATIONAL CONGRESS OF THE LATIN AMERICAN STUDIES ASSOCIATION, 25., 2004, Las Vegas. Proceedings... Las Vegas: [S.n.], 2004.

ALCÁNTARA SÁEZ, M. ¿Instituciones o máquinas ideológicas? Origen, programa y organización de los partidos políticos latinoamericanos. Barcelona: ICPS, 2004.

Elections in Latin America 2009-2011: a comparative analysis. Working paper, n. 386, p. 1-61, 2012.

ALCÁNTARA, M.; RIVAS, C. Las dimensiones de la polarización partidista en América Latina. Política y gobierno, v. 14, n. 2, p. 349-390, 2007.

AMARAL, S.; STOKES, S. C. (Org.). La democracia local en Argentina: clientelismo, capital social, e innovación. Buenos Aires: Universidad Tres de Febrero, 2005.

BENOIT, K.; LAVER, M. Party policy in modern democracies. Milton: Nova York: Routledge, 2006.

CANACHE, D. Urban poor and political order. In: MCCOY, J. L.; MYERS, D. (Org.). The unraveling of representative democracy in Venezuela. Baltimore: Johns Hopkins University Press, 2004. p. 33-49.

CANNON, B. Class/race polarisation in Venezuela and the electoral success of Hugo Chávez: a break with the past or the song remains the same? Third world quarterly, v. 29, n. 4, p. 731-748, 2008.

CHERESKY, I. Cambio de rumbo y recomposición política en Argentina: Néstor Kirchner cumple un año de gobierno. In: INTERNATIONAL CONGRESS OF THE LATIN AMERICAN STUDIES ASSOCIATION, 25., 2004, Las Vegas. Proceedings... Las Vegas: [S.n.], 2004.

COPPEDGE, M. A classification of Latin American political parties. Working paper, n. 244, p. 1-82, 1997.

ELLNER, S.; HELLINGER, D. (Org.). La política venezolana en la época de Chávez: clases, polarización y conflicto. Caracas: Nueva sociedad, 2003.

ESCOLAR, M. et al. Últimas imágenes antes del naufragio: las elecciones del 2001 en la Argentina. Desarrollo económico, v. 42, n. 165, p. 25-43, 2002.

HEATH, O. Explaining the rise of class politics in Venezuela. Bulletin of Latin American research, v. 28, n. 2, p. 185-203, 2009.

HELLINGER, D. Visión política general: la caída del puntofijismo y el surgimiento del chavismo. In: ELLNER, S.; HELLINGER, D. (Org.). La política venezolana en la época de Chávez: clases, polarización y conflicto. Caracas: Nueva Sociedad, 2003. p. 43-74

When "no" means "yes to revolution": electoral politics in Bolivarian Venezuela. In: ELLNER, S.; TINKER SALAS, M. (Org.). Venezuela: Hugo Chávez and the decline of an "exceptional democracy". Lanham: Rowman \& Littlefield, 2007. p. 157-184.

INGLEHART, R. Culture shift in advanced industrial society. Princeton: Princeton University Press, 1990.

INGLEHART, R.; WELZEL, C. Modernization, cultural change, and democracy: the human development sequence. Cambridge: Cambridge University Press, 2005.

KITSCHELT, H. et al. Latin American party systems. Nova York: Cambridge University Press, 2010.

LAMOUNIER, B. Estrutura institucional e governabilidade na década de 90. In: REIS VELLOSO, J. P. dos (Org.). O Brasil e as reformas políticas. Rio de Janeiro: José Olympio, 1992. p. 23-47. 
LÓPEZ MAYA, M. Hugo Chávez Frías: sum movimiento y presidencia. In: ELLNER, S.; HELLINGER, D. (Org.). La política venezolana en la época de Chávez: chases, polarización y conflicts. Caracas: Nueva Sociedad, 2003. p. 97-120.

LÓPEZ MAYA, M.; LANDER, L. E. Venezuela: las elecciones presidenciales de 2006 ¿Hacia el socialismo del siglo XXI? Cuadernos del cendes, v. 24, n. 64, p. 1-21, 2007.

MADRID, R. L. The rise of ethnic politics in Latin America. Nova York: Cambridge University Press, 2012.

MAINGON, T. Síntomas de la crisis y de la deslegitimación del sistema de partidos en Venezuela. In: INTERNATIONAL CONGRESS OF THE LATIN AMERICAN STUDIES ASSOCIATION, 25., 2004, Las Vegas. Proceedings... Las Vegas: [S.n.], 2004.

MAINWARING, S.; PÉREZ-LIÑÁN, A. Democracies and dictatorships in Latin America: emergence, survival, and fall. Nova York: Cambridge University Press, 2013.

MAIR, P. Searching for the positions of political actors: a review of approaches and a critical evaluation of expert surveys. In: LAVER, M. (Org.). Estimating the policy positions of political actors. Londres: Rutledge, 2001. p. 10-30.

MUSTAPIC, A. M. Argentina: la crisis de representación y los partidos politicos. América Latina hoy, v. 32, p. 163183, 2002.
DA PERDA DE LEGITIMIDADE À POLARIZAÇÃO ...

NOVARO, M. (Org.). El derrumbe politico en el ocaso de la convertibilidad. Buenos Aires: Norma, 2002.

RAMOS JIMÉNEZ, A. Los partidos politicos en las democracias latinoamericanas. Merida: Universidad de los Andes, 1995

ROBERTS, K. M. Social correlates of party system demise and populist resurgence in Venezuela. Latin American politics and society, v. 45, n. 3, p. 35-57, 2003.

ROSAS, G.; ZECHMEISTER, E. J. Ideological dimensions and left-right semantics in Latin America. INTERNATIONAL CONGRESS OF THE LATIN AMERICAN STUDIES ASSOCIATION, 22., 2000, Miami. Proceedings... Miami: [S.n.], 2000.

STOKES, S. C. et al. Brokers, voters, and clientelism: the puzzle of distributive politics. Nova York: Cambridge University Press, 2013.

VAN COTT, D. L. From movements to parties in Latin America: the evolution of ethnic politics. Nova York: Cambridge University Press, 2005.

WIESEHOMEIER, N.; BENOIT, K. Parties and presidents in Latin America: data from expert surveys in 18 Latin American countries, 2006-2007. [S.l.: S.n.], 2007. Disponível em: <www.wiesehomeier.net>. Acesso em: 31 ago. 2016.

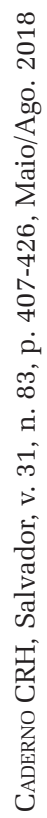

422 


\section{ANEXO}

\section{Argentina}

Especialistas, por ordem alfabética: Andrés Malamud (Universidade de Lisboa), Aníbal Pérez-Liñán (University of Notre Dame) e Ernesto Calvo (University of Maryland)

\section{Especialista 1, por ordem de resposta:}

Ação pela República (SR, P, M e 0); Acordo Cívico e Social (SCL, P, M e 0); Aliança Autonomista Liberal/Democrata Progressista/ UCEDE (SR, P, M e 0); Aliança de Centro (SR, P, M e 0); Aliança FREGEN/FREPASO (SCL, P, M e 0); Aliança Esquerda Unida (-, $\mathrm{P}, \mathrm{M}$ e 0); Aliança para o Trabalho, Justiça e Educação (SCL, PC, M e 0); Autodeterminação e Liberdade (SCL, P, M e 0); Autodeterminação e Liberdade/Democrata Progressista (SCL, $\mathrm{P}, \mathrm{M}$ e 0); Bloquista (SC, C, M e 0); Coalizão Cívica - ARI (SCL, P, M e 0); Compromisso Federal (SC, C, M e 0); Frente Acordo Cívico e Social (SCL, P, M e 0); Frente Cívica (SCL, $\mathrm{P}, \mathrm{M}$ e 0); Frente Cívica de Córdoba (SCL, P, $\mathrm{M}$ e 0); Frente Cívica Jujenha (SC, P, M e 0); Frente Cívica para a Vitória (SCL, P, M e 0); Frente Cívica por Santiago (SC, PC, M e 0); Frente Cívica e Social (SC, P, M e 0); Frente Cívica e Social de Catamarca (SCL, P, M e 0); Frente de Esquerda e dos Trabalhadores (SL, $\mathrm{P}, \mathrm{M}$ e 0); Frente da Vitória (SCL, PC, M e 0); Frente Progressista Cívica e Social (SCL, P, $\mathrm{M}$ e 0); Frente Renovadora (SC, PC, M e 0); Frente Renovadora, a de Sergio Massa (SC, PC, $\mathrm{M}$ e 0); FREPASO (SCL, P, M e 0); Força Republicana (SR, PC, M e 0); GEN (Geração para um Encontro Nacional, SC, PC, M e 0); MODIN (SR, PC, M e 0); Movimento Popular Jujenho (SC, C, M e 0); Movimento Popular Neuquino (SC, C, M e 0); Partido Humanista (SC, P, M e 0); Partido Intransigente (SCL, P, $\mathrm{M}$ e 0); Partido Obreiro (SL, P, M e 0); Partido Renovador de Salta (SC, PC, M e 0); Partido Socialista (SCL, PC, M e 0); PJ (SC, PC, M e 0); PJ - Concertação Justicialista para a Mudança (SC, PC, M e 0); PJ - Frente Justicialista (SC, PC, M e 0); PJ - Frente Justicialista para a Vitória (SCL, PC, M e 0); PJ - Frente para a Vitória (SCL, PC, M e 0); PRO (SCR, PC, M e 0);
PRO - Frente Democrata (SCR, PC, M e 0); PRO - Frente União PRO Dignidade (SCR, PC, M e 0); PRO - Santa Fé Federal (SCR, PC, M e 0); PRO - União PRO (SCR, PC, M e 0); RECRIAR - União para Recriar Buenos Aires (SCR, P, M e 0); UCEDE (SR, P, M e 0); UCR (SC, PC, M e 0 ); UCR - Intransigente (SCL, P, M e 0); UNEN (SC, $\mathrm{P}, \mathrm{M}$ e 0 ).

\section{Especialista 2, por ordem de resposta:}

Ação pela República (SCR, -, - e -); Aliança de Centro (SCR, P, - e -); Aliança Esquerda Unida (SL, -, - e -); Aliança para o Trabalho, Justiça e Educação (SCL, -, - e -); Bloquista (O, -, - e -); Coalizão Cívica - ARI (SC, P, - e -); Compromisso Federal (P, -, - e -); Frente Renovadora, a de Sergio Massa (P, -, - e -); FREPASO (SCL, P, - e -); Força Republicana (SR, P, - e -); GEN (SCL, P, - e -); MODIN (SR, P, - e -); Movimento Livres do Sul (SCL, -, - e -); Movimento Popular Foguino (O, -, - e -); Movimento Popular Jujenho (O, -, - e -); Movimento Popular Neuquino (O, -, - e -); Movimento Solidário Popular (O, -, - e -); Partido Branco dos Aposentados (P, -, - e -); Partido de Trabalhadores pelo Socialismo (SL, -, - e -); Partido Federal Foguino (O, -, - e -); Partido Humanista (-, P, PM e -); Partido Obreiro (SL, P, - e -); Partido Renovador de Salta (SCR, -, - e -); Partido Socialista (SC, -, - e -); PJ (O, -, - e -); Projeto Sul (SCL, P, - e -); UCEDE (SCR, P, - e -); UCR (SC, -, - e -); UCR - SUMA (SC, -, - e -); UNEN (SC, -, - e -); União para Viver Melhor (SC, -, - e -).

\section{Especialista 3, por ordem de resposta:}

Ação Federal para Buenos Aires (-, -, - e 0); Ação pela República (-, -, - e 0); Acordo Cívico e Social (-, -, - e 0); Aliança Autonomista Liberal/Democrata Progressista/UCEDE (SCR, -, $\mathrm{M}$ e 0); Aliança de Centro (SCR, -, M e 0); Aliança FREGEN/FREPASO (SCL, -, MPM e 0); Aliança Grande (-, -, - e 0); Aliança Esquerda Unida (SL, -, M e 0); Aliança Opositora (-, -, - e 0); Aliança para o Trabalho, Justiça e Educação (SC, -, MPM e 0); Aliança para Todos (-, -, - e 0); Aliança por Mendoza (-, -, - e 0); Aliança por San Juan (-, -, - e 0); Aliança Santacruzenha (-, -, - e 0); Aliança Santafesina (-, -, - e 0); Aliança Saltenha (-, -, - e 0); Aliança Unidade 
Socialista (-, -, - e 0); Autodeterminação e Liberdade (-, -, - e 0); Autodeterminação e Liberdade/Democrata Progressista (-, -, - e 0); Bloquista (-, -, - e 0); Coalizão Cívica - ARI (SCL, -, PM e 0); Compromisso Federal (P, -, M e 0); Confederação Federalista Independente (-, -, - e 0); Desenvolvimento e Justiça (-, -, - e 0); Diálogo por Buenos Aires (-, -, - e 0); Encontro para a Mudança (-, -, - e 0); Encontro Popular (-, -, - e 0); Encontro Popular para a Vitória (-, -, - e 0); Encontro por Corrientes (-, -, - e 0); FISCAL (-, -, - e 0); Frente Acordo Cívico e Social (-, -, - e 0); Frente Alternativa Pampeana (-, -, - e 0); Frente Ampla Formosenha (-, -, - e 0 ); Frente Ampla Progressista (-, -, - e 0); Frente Cívica (-, -, - e 0); Frente Cívica de Córdoba (-, -, - e 0); Frente Cívica Jujenha (-, -, - e 0); Frente Cívica para a Vitória (-, -, - e 0); Frente Cívica por Santiago (-, -, - e 0); Frente Cívica e Social (-, -, - e 0); Frente Cívica e Social de Catamarca (-, -, - e 0); Frente Cívica e Social na Terra do Fogo (-, -, - e 0); Frente Compromisso para a Mudança (-, -, - e 0); Frente de Esquerda e dos Trabalhadores (-, -, - e 0); Frente da Unidade (-, -, - e 0); Frente da Vitória (-, -, - e 0); Frente do Povo Riojano (-, -, - e 0); Frente de Unidade Provincial (-, -, - e 0); Frente Entrerriana para a Produção e o Trabalho (-, -, - e 0); Frente Federal (-, -, - e 0); Frente Fundacional para a Mudança (-, -, - e 0); Frente Jujenha (-, -, e 0); Frente Justiça para Santa Fé (-, -, - e 0); Frente Justiça, União e Liberdade (-, -, - e 0); Frente Movimento Popular (-, -, - e 0); Frente Movimento Vida e Compromisso (-, -, - e 0);

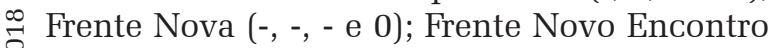
. (-, -, - e 0); Frente Pampeana Cívica e Social (-, -, - e 0); Frente para a Mudança (-, -, - e 0); Frente para a Unidade (-, -, - e 0); Frente para Todos (-, -, - e 0); Frente Polo Social (-, -, - e o) 0 ; Frente Popular (-, -, - e 0); Frente Popular Bonaerense (-, -, - e 0); Frente Popular Riojana (-, -, - e 0); Frente Popular Saltenha (-, -, - e 0); Frente pela Inclusão Social (-, -, - e 0); Frente pela Integração (-, -, - e 0); Frente pela Lealdade (-, -, - e 0); Frente por um Novo País (-, -, - e 0); Frente Produção e Trabalho (-, -, - e 0); Frente Progressista Cívica e Social (-, -, - e 0); Frente Proposta Federal (-, -, - e 0); Frente Projeto Corrientes (-, -, - e 0); Frente Renovadora (SC, F $\mathrm{C}, \mathrm{M}$ e 0); Frente Renovadora, a de Sergio Massa (SC, C, M e 0); Frente Renovadora da Concordia (-, -, - e 0); Frente Social Entre Ríos Tem Futuro (-, -, - e 0); Frente Unida por
Catamarca (-, -, - e 0); Frente União por Buenos Aires (-, -, - e 0); Frente União por San Juan (-, -, - e 0); FREPASO (SCL, P, MPM e 0); Força Cívica Riojana (-, -, - e 0); Força de Unidade Popular (-, -, - e 0); Força Portenha (-, -, - e 0); Força Republicana (-, -, - e 0); GEN (-, -, - e 0); Instrumento Eleitoral pela Unidade Popular (-, -, - e 0); Lema Riojano para Trabalho e Produção (-, -, - e 0); MODIN (SR, PC, M e 0); Movimento Federalista Pampeano (-, -, - e 0); Movimento Livres do Sul (-, -, - e 0); Movimento Popular Foguino (-, -, - e 0); Movimento Popular Jujenho (-, -, - e 0); Movimento Popular Neuquino (SCR, C, M e 0); Movimento Solidário Popular (-, -, - e 0); Novo Espaço Entrerriano (-, -, - e 0); Partido Ação Chubutense (-, -, - e 0); Partido Autonomista (-, -, - e 0); Partido Branco dos Aposentados (-, -, - e 0); Partido Conservador Popular (-, -, - e 0); Partido da Cidade (-, -, e 0); Partido da Cultura, da Educação e do Trabalho (-, -, - e 0); Partido da Renovação Democrática (-, -, - e 0); Partido Democrata (-, -, - e 0); Partido Democrata Cristão (XCL, -, M e 0); Partido Democrata Progressista (SCR, -, M e 0); Partido de Trabalhadores pelo Socialismo (-, -, - e 0); Partido Fé (-, -, - e 0); Partido Federal Foguino (-, -, - e 0); Partido Humanista (SCL, -, PM e 0); Partido Intransigente (SCL, -, M e 0); Partido Liberal (-, -, - e 0); Partido Nacionalista Constitucional UNIR (-, -, - e 0); Partido Novo (-, -, - e 0); Partido Obreiro (SL, P, M e 0); Partido Renovador de Salta (-, -, - e 0); Partido Socialista (SCL, -, M e 0); Partido Socialista Autêntico (-, -, - e 0); Partido Socialista Popular (-, -, - e 0); Partido União Celeste e Branco (-, -, - e 0); PJ (SC, PC, M e 0); PJ - Concertação Justicialista para a Mudança (-, -, - e 0); PJ - Frente Chaco Merece Mais (-, -, - e 0); PJ Frente Fundacional Justicialista (-, -, - e 0); PJ - Frente Justicialista (SC, PC, M e 0); PJ - Frente Justicialista Bonaerense (SC, PC, M e 0); PJ Frente Justicialista Chaco (-, -, - e 0); PJ - Frente Justicialista Compromisso para Mendoza (-, -, - e 0); PJ - Frente Justicialista da Esperança (-, -, - e 0); PJ - Frente Justicialista do Chubut (-, -, - e 0); PJ - Frente Justicialista de Libertação (-, -, - e 0); PJ - Frente Justicialista do Povo (-, -, - e 0); PJ - Frente Justicialista Entrerriana (-, -, - e 0); PJ - Frente Justicialista É Possível (-, -, - e 0); PJ - Frente Justicialista para a Vitória (SCL, PC, M e 0); PJ - Frente Justicialista para a Mudança (-, -, - e 0); PJ - Frente Justicialista Popular (-, -, - e 0); PJ - Frente Justicialista Provincial (-, -, - e 0); 
PJ - Frente Justicialista Solidária (-, -, - e 0); PJ - Frente Justicialista Todos para a Mudança (-, -, - e 0); PJ - Frente para a Vitória (SCL, PC, M e 0); PJ - Frente para a Vitória Riojana (SCL, PC, M e 0); PJ - Frente para a Vitória Santacrucenha (SCL, PC, M e 0); PJ - Partido Justicialista La Pampa (-, -, - e 0); PJ - Peronismo Mais ao Sul (-, -, - e 0); PRO (SCR, P, PM e 0); PRO - Frente Democrata (SCR, P, PM e 0); PRO - Frente União PRO Dignidade (SCR, P, PM e 0); PRO - Santa Fé Federal (SCR, P, PM e 0); PRO - União PRO (SCR, P, PM e 0); Projeto Sul (SL, P, MPM e 0); RECRIAR - União para Recriar Buenos Aires (-, -, - e 0); Salta Somos Todos (SCR, P, PM e 0); Todos por Entre Ríos (SCR, P, PM e 0); UCEDE (SR, P, M e 0); UCR (SC, - , MPM e 0); UCR Aliança para Tucuman (SC, - , MPM e 0); UCR - Aliança pela Pampa (SC, - , MPM e 0); UCR Aliança pela Patagônia (SC, - , MPM e 0); UCR - Concertação para o Desenvolvimento (SC, - , MPM e 0); UCR - Frente Mudemos para Crescer (SC, - , MPM e 0); UCR - Frente Cívica Federal (SC, - , MPM e 0); UCR - Frente de Todos (SC, , MPM e 0); UCR - Intransigente (SC, - , MPM e 0); UCR - Movimento Popular Catamarquenho (SC, - , MPM e 0); UCR - SUMA (SC, - , MPM e 0); UCR - UDESO Mendoza (SC, - , MPM e 0); UCR - UDESO Salta (SC, - MPM e 0); UNA (-, -, - e 0); Uma Nova Opção (-, -, - e 0); UNEN (SC, -, - e 0); Unidade Bonaerense (-, -, - e 0); Unidade Federalista (-, -, - e 0); Unidos pela Liberdade e pelo Trabalho (-, -, - e 0); Unidos por Salta (-, -, - e 0); Unidos por San Juan (-, -, - e 0); União para o Desenvolvimento Social (-, -, - e 0); União para Viver Melhor (-, -, - e 0 ); União pelo Chaco (-, -, - e 0); União por Córdoba (-, -, - e 0); União por Entre Ríos (-, -, - e 0); União por um Novo Chaco (-, -, - e 0).

\section{Venezuela}

Especialistas, por ordem alfabética: Jennifer Cyr (University of Arizona) e Zaira Reverón (Universidad Simón Bolívar)

\section{Especialista 1, por ordem de resposta:}

$\mathrm{AD}$ (SCL, -, - e -); ABP (SR, -, - e -); AD Oposição (SCL, -, - e -); APC (Aliança para a Mudança, SL, -, - e -); Abertura (SCL, -, - e -); Causa Comum (SCR, -, - e -); CONIVE (O, -, - e
-); Convergência (XCR, -, - e -); COPEI (XC, -, - e -); CCN (Cruzada Cívica Nacionalista, SR, -, - e -); Contas Claras (SCL, -, - e -); F-1 (SC, -, - e -); FND (Frente Nacional Democrática, SR, -, - e -); FDP (Força Democrática Popular, SL, -, - e -); FUNDACIDI (O, -, - e -); GE (Gente Emergente, SCL, -, - e -); IPFN (SC, -, - e -); IRENE (O, -, - e -); LCR (SCL, -, - e -); LS (Liga Socialista, SL, -, - e -); MinhaZulia (O, -, - e -); MAN (U, -, - e -); MAS (SCL, -, - e -); MIN (Movimento de Integridade Nacional, SCR, -, - e -); MDPBR (SL, -, - e -); MEP (SL, -, - e -); MENI (Movimento Nacional Eleitoral Independente, U, -, - e -); MiGato (U, -, - e -); MIR (Movimento de Esquerda Revolucionária, SL, -, - e -); MPV (Movimento Progressista da Venezuela, SCL, -, - e -); NA (U, -, - e -); NGD (SC, -, - e -); OFM (Organização Força em Movimento, U, -, - e -); OPINA (Opinião Nacional, SC, -, - e -); ORA (O, -, - e -); PCV (SCL, -, - e -); PNI (Partido Nacional Integracionista, SR, -, - e -); PRIN (Partido Revolucionário de Integração Nacionalista, SL, -, - e -); PSUV (P, -, - e -); PSV (U, -, - e -); PPT (SC, -, - e -); PODEMOS (SCL, -, - e -); PJ (SC, -, - e -); Projeto Venezuela (SC, -, - e -); PUAMA (Povos Unidos Multiétnicos do Amazonas, O, -, - e 1); Renovação (U, -, - e -); SI (Solidariedade Independente, O, -, - e -); UNT (SCL, -, - e -); UDH (Unidos pelos Direitos Humanos, O, -, - e -); UPV (Unidade Popular Venezuelana, SL, -, - e -); URD (SCL, -, - e -); VUC (Vanguarda Unitária Comunista, SL, -, - e $-)$.

Especialista 2, por ordem de resposta:

$\mathrm{AD}$ (SC/SCR, PC, M e 0); ABP (SCL, PC, M e 0); CONIVE (SL, P, PM e 1); COPEI (XCR, PC, M e 0); IRENE (P, -, M e 0); LCR (SCL, P/PC, M e 0); MAS (SCL, P/PC, M e 0); MDP-BR (SL, P, M e 0); MiGato (P, NS, M e 0); ORA (XCR, P, PM e 0); PCV (SL, P, M e 0); PSUV (SL, PC, M e 0); PPT (SL, P, M e 0); PODEMOS (SL, P, M e 0); PJ (SCR, P/PC, M e 0); Projeto Venezuela (XCR, P, $\mathrm{M}$ e 0); UNT (SCL, P, M e 0). 


\section{FROM THE LOSS OF LEGITIMACY TO POLARIZATION: the parties and party systems of Argentina and Venezuela}

\author{
João Carlos Amoroso Botelho
}

The paper updates the classifications of Coppedge (1997) for the parties of Argentina and Venezuela, adding to the original dimensions of left-right and Christian or secular three others, programmatic or clientelistic, materialistic or post-materialistic and ethnic electoral appeal. To do so, it is based on the literature and on an expert survey. One conclusion is that there was little variation in relation to Coppedge's assessments, with the main parties located around the center, except for the PSUV in Venezuela, which was classified as secular left. Regarding the party systems, the two countries have transited from the legitimacy loss of its traditional parties until the early 2000s to scenarios characterized at the time of this classification by polarization around the adhesion or opposition to kirchnerismo or chavismo. Unlike the Venezuelan case, the polarization in Argentina was more between supporting or opposing the government of each moment than in ideological terms.

Keywords: Classification. Idelogy. Political Parties. Argentina. Venezuela.

\author{
DE LA PERTE DE LA LÉGITIMITÉ À LA \\ POLARISATION: les partis et les systèmes de \\ partis en Argentine et au Venezuela
}

João Carlos Amoroso Botelho

L'article jour évaluations de Coppedge (1997) pour les parties de l'Argentine et Venezuela, en ajoutant aux dimensions originales de gauche-droite et chrétien ou laïque trois autres: programmatiques ou clientélistes, matérialistes ou post-matérialistes et de recours électoral ethnique. Pour ce faire, il est basé sur la littérature et sur une enquête auprès des experts. Une conclusion est qu'il y avait peu de variation par rapport aux évaluations de Coppedge, avec les principales parties concentrées autour du centre, à l'exception du PSUV au Venezuela, qui a été classé comme laïque gauche. En ce qui concerne les systèmes de partis, les deux pays ont transité par la perte de légitimité des partis traditionnels jusqu'au début des années 2000 pour les scénarios qui ont été caractérisés au moment de cette classification par la polarisation autour de l'adhésion ou d'opposition à kichnerismo ou chavismo. Contrairement au cas du Venezuela, la polarisation en Argentine était plus entre le soutien ou combattre le gouvernement à un moment qu'en termes idéologiques.

Mots CLÉs: Classement. Idéologie. Partis Politiques. Argentine. Venezuela. de Ciência Política e do Programa de Pós-Graduação em Ciência Política da Universidade Federal de Goiás. Coordena o Núcleo de Estudos e Pesquisas em América Latina e Política Comparada (NEPAC) e realiza pesquisas sobre temas como regimes e instituições políticas e integração regional. Publicou, entre outros trabalhos em periódicos nacionais e internacionais, o livro La creación y la evolución de Unasur, Curitiba: Juruá Editora, 2013. 